\title{
Trajectories of Parental Engagement in Early Childhood Among Dual-Earner Families: Effects on Child Self-Control
}

\author{
Tiago Ferreira, Joana Cadima, Marisa Matias, \\ Joana Marina Vieira, and Teresa Leal \\ University of Porto
}

\author{
Karine Verschueren \\ KU Leuven
}

\author{
Paula Mena Matos \\ University of Porto
}

\begin{abstract}
Parental engagement in positive activities with the child may show significant variation across time, assuming a crucial influence on child development. In dual-earner families, work-family conflict can interfere with parental engagement, with negative consequences for children's behavior. The current study examined the change trajectories of mothers' and fathers' engagement in early childhood, analyzing whether these trajectories are influenced by parents' work-family conflict and whether they predict child behavioral self-control. Data from 156 four-year-old children (67 girls) from dual-earner families were collected annually for 3 consecutive years, through mothers', fathers', and teachers' reports. Results from latent growth curve analysis revealed mothers' engagement remained stable across time while fathers' engagement had a significant increase over time. The negative association between work-family conflict and parental engagement was constant over time both for mothers and fathers. For mothers, initial levels of engagement positively predicted child behavioral self-control. As for fathers, both the initial level and positive change in engagement positively predicted child self-control. These findings emphasize the role of parental engagement in fostering child behavioral adjustment, underlining the need for considering work-family dynamics to understand changes in parental engagement.
\end{abstract}

Keywords: maternal engagement, paternal engagement, work-family conflict, children's self-control

Parental involvement is a broad construct that covers the different ways in which mothers and fathers can participate in their child's life. Parental engagement is a primary component of parental involvement (Pleck, 2010). It refers to parents' direct interactions with the child, through caretaking and shared activities, and can be used to characterize both mothers' and fathers' participation in children's lives (Pleck, 2010). Parental engagement has been recognized as a positive predictor for children's cognitive and socioemotional development (Amato \& Rivera, 1999; Cabrera, Shannon, \& Tamis-LeMonda, 2007; Lang et al., 2014). Although parental engagement may take place within a wide range of activities, literature has been mainly concentrated on parental engage-

This article was published Online First November 20, 2017.

Tiago Ferreira, Joana Cadima, Marisa Matias, Joana Marina Vieira, and Teresa Leal, Faculty of Psychology and Educational Sciences, Center for Psychology, University of Porto; Karine Verschueren, Faculty of Psychology and Educational Sciences, KU Leuven; Paula Mena Matos, Faculty of Psychology and Educational Sciences, Center for Psychology, University of Porto.

This research was supported by FEDER, COMPETE program, and by the Portuguese Foundation for Science and Technology, PTDC/MHCCED/5218/2012 grant.

Correspondence concerning this article should be addressed to Paula Mena Matos, Faculdade de Psicologia e de Ciências da Educação da Universidade do Porto, Rua Alfredo Allen 4200-135 Porto, Portugal. E-mail: pmmatos@fpce.up.pt ment in activities that are likely to foster child development, also known as positive engagement activities (Pleck, 2010). Playing games, reading, or taking a walk in the park are some examples of positive engagement activities that can be shared by parents and children. The current study specifically focuses on the frequency of time parents spend in a set of positive engagement activities with their children, including time spent in planning free time together, going on outings, doing outdoor activities, playing games and working on joint projects with the child. Children can benefit greatly from sharing time with their parents in positive engagement activities, as these activities constitute privileged opportunities for intensive and positive parent-child interactions. In dualearner families, parents' engagement in positive activities is particularly important to address, as mothers and fathers struggle with demanding work schedules and may have reduced opportunities for interacting with their children. Framed within an ecological perspective (Bronfenbrenner \& Morris, 2006), the current study examines the change trajectories of parental engagement from preschool to first grade, investigating whether these trajectories are affected by parents' work-family conflict (WFC) and whether they predict child self-control.

\section{Trends in Mothers' and Fathers' Engagement}

Women's increasing participation in the labor force and the rising of gender equality and intensive parenting ideologies are some of the remarkable social-cultural changes that have taken place in western societies for the last few decades. These changes 
are slowly attenuating a traditional unbalanced conception of mothers' and fathers' participation in child rearing (Bianchi, 2000; Lamb, 2000; Lareau, 2002). Although mothers are still responsible for the main share of parenting activities, there is a large body of evidence consistently suggesting that differences between mothers and fathers are gradually decreasing (McBride \& Mills, 1993; Pleck, 2010; Yeung, Sandberg, Davis-Kean, \& Hofferth, 2001). Using data from a nationally representative sample of North American families, Yeung et al. (2001) showed that, relative to fathers, mothers still spend more time involved or accessible to children. Mothers' involvement is particularly high in caring, teaching, and household activities, whereas fathers' relative contribution in these domains is much lower (Yeung et al., 2001). However, differences in the amount of time fathers and mothers spend in positive engagement activities, such as play and social activities, are less manifest (Yeung et al., 2001). This trend is particularly evident among parents from dual-earner families. Indeed, fathers' participation in positive engagement activities, such as leisure activities, is higher among dual-earner families than in single-earner families (Crouter, Perry-Jenkins, Huston, \& McHale, 1987; Zick, Bryant, \& Österbacka, 2001). This may be because parents from dual-earner families tend to share more egalitarian perspectives on gender roles, recognizing that both, mothers and fathers, have important contributions to child development (Bonney, Kelley, \& Levant, 1999; Meteyer \& Perry-Jenkins, 2010). Despite the evidence suggesting that maternal employment may trigger greater paternal engagement (Crouter et al., 1987; Zick et al., 2001), the current understanding of how mothers' and fathers' work demands influence their parental engagement is still limited. Specifically, more studies are needed to further understand how mothers' and fathers' engagement in positive activities with the child is affected by the way parents balance their work and family roles. Moreover, longitudinal research on mothers' and fathers' engagement is still relatively scarce (Lang et al., 2014; Meteyer \& Perry-Jenkins, 2010; Wood \& Repetti, 2004). In one of the few studies examining changes in parents' engagement in positive activities during children's infancy (at 3, 6, and 9 months old), Lang et al. (2014) found that mothers and fathers increased their engagement with the child at similar growth rates. During middle childhood, fathers display increasing levels of global involvement while mothers display decreasing levels of global involvement (Wood \& Repetti, 2004). The aforementioned studies suggest that parental engagement is subject to cross-time variations. Most of the available research, however, has addressed parental engagement as a stable component of parenting, disregarding variations in parents' engagement over time and making it difficult to observe within-person variations on parental engagement over time. Therefore, more longitudinal research on parents' engagement is necessary, specifically, examining the trajectories of mothers' and fathers' engagement in positive activities during the early childhood period.

\section{Work-Family Dynamics and Parental Engagement}

Understanding the link between work-family dynamics and parental engagement is particularly relevant in dual-earner families, as this type of family organization has substantially increased in the last half century (Gottfried, Gottfried, \& Bathurst, 2002). Also, mothers and fathers from dual-earner families are confronted with exceptional work and family demands, likely affecting their avail- ability to engage in child-rearing activities (Bonney et al., 1999; Danner-Vlaardingerbroek, Kluwer, van Steenbergen, \& van der Lippe, 2013; Meteyer \& Perry-Jenkins, 2010; Zick et al., 2001). Although some structural conditions of parents' work environment (e.g., long working hours, atypical schedules, and husband-wife wage differentials) are associated with parental involvement in dual-earner families (Hook \& Wolfe, 2013; Wood \& Repetti, 2004; Yeung et al., 2001), the way parents perceive balance between their work and family demands exerts a strong influence on parenting (Cinamon, Weisel, \& Tzuk, 2007; Corwyn \& Bradley, 1999; Perry-Jenkins, Repetti, \& Crouter, 2000; Vieira, Matias, Ferreira, Lopez, \& Matos, 2016). Some studies reported that parents' WFC, meaning the experience perceived by the parents as not having enough time and energy to manage all work and family responsibilities, has a negative effect on their psychological availability and socioemotional investment in their children (Matias et al., 2017; Corwyn \& Bradley, 1999; Danner-Vlaardingerbroek et al., 2013). The experience of WFC may have particularly negative implications for parents' availability to engage in activities that go beyond basic caretaking, namely spending time with the child in positive engagement activities. WFC may interfere with parents' availability to engage in positive joint activities with their child, particularly when parents experience time constraints, high levels of work-related stress, and lack of compatibility between workbehaviors and family living (Greenhaus \& Beutell, 1985). Few studies have previously examined the impact of mothers' and fathers' WFC on their engagement in shared positive activities that are likely to foster child development. In a cross-sectional study, Vieira et al. (Vieira, Matias, Lopez, \& Matos, 2016) observed that mothers' WFC was negatively associated with their amount of time in positive engagement activities with the child. They also found that parents' WFC was associated both with their own and their partners' frustration regarding child and parenting activities. These results are consistent with the notion of interdependence between family members and reinforce the need to consider the crossover effects between mothers' and fathers' work-family balance and parental engagement (Casper, Eby, Bordeaux, Lockwood, \& Lambert, 2007; Pleck, 2010; Westman, 2001).

Parents' work-family dynamics may relate to changes in parental engagement over time (Lang et al., 2014; Meteyer \& PerryJenkins, 2010; Wood \& Repetti, 2004; Yeung et al., 2001). Lang et al. (2014) examined trajectories of father and mother engagement in positive activities, such as playing with the child, creating arts or crafts with the child, and soothing or holding the child, over the first 9 months of the child's life. Their results established a negative connection between work conditions and parental positive engagement over time, showing that the growth of parental engagement in nonwork days over time is greater than the growth of parental engagement in work days (Lang et al., 2014). Wood and Repetti (2004) examined changes in parental involvement for 3 consecutive years regarding a broad set of activities, including playing with child, getting the child ready for bed and teaching skills. They found mothers' working hours had a negative effect on mothers' caregiving involvement and a positive effect on fathers' caregiving involvement over time. Meteyer and Perry-Jenkins (2010) addressed changes on father involvement over the first year of parenthood, examining fathers' participation in both caretaking (e.g., feeding, changing diapers, soothing, getting up at night) and positive engagement activities (e.g., playing, reading or singing, 
taking on an outing). Their results suggest mothers' working hours is a significant positive predictor of fathers' involvement over time (Meteyer \& Perry-Jenkins, 2010).

Despite these few studies, there are clear gaps in the available literature linking work-family dynamics and changes in parental engagement. The few available works have addressed the links between parents' work dynamics and parental engagement mainly by examining whether levels of parental engagement over time are influenced by parents' working hours (Meteyer \& Perry-Jenkins, 2010; Wood \& Repetti, 2004). Although long working hours can be associated with increasing WFC, parents with similar work schedules may display significant differences in their subjective experience of WFC (Cooklin et al., 2016; Michel, Kotrba, Mitchelson, Clark, \& Baltes, 2011). Furthermore, despite the relative stability in their working hours across time, parents may experience important variations in perceived WFC over time (Cooklin et al., 2016; Rantanen, Kinnunen, Pulkkinen, \& Kokko, 2012). Parents' work-related dynamics may vary over time and interfere with the type, amount, and quality of family time, producing variations in the rates of parental engagement. Therefore, there is a need for further research investigating the varying impact of parents' WFC on the change trajectories of parental engagement in positive activities, specifically during the early childhood period.

\section{Parental Engagement and Child Self-Control}

According to Bronfenbrenner's bioecological theory, human development is driven by reciprocal interactive processes between the developing person and its complex environment (Bronfenbrenner \& Morris, 2006). These proximal processes take place at the microsystem level providing the interactive setting for human development. Parent-child dyadic interactions may provide optimal opportunities for the occurrence of proximal processes that may foster crucial developmental acquisitions. Parental engagement assumes a central role during early childhood, where developmental changes are remarkably fast and critical for children's later social-emotional functioning and behavioral adjustment (Shonkoff \& Phillips, 2000). Specifically, the period from preschool to early elementary school is widely recognized as a crucial stage for the development of social-emotional competence. During this stage, children are expected to substantially improve their abilities to maintain adaptive interactions with peers and adults (Garner, Mahatmya, Moses, \& Bolt, 2014; Williford, Vick Whittaker, Vitiello, \& Downer, 2013). One of the main developmental tasks during the preschool years is the acquisition of the ability to regulate emotions and behaviors in social interactions (Shonkoff \& Phillips, 2000). The development of internal structures and mechanisms of regulation and the emergence of self-control during the first years of life is pivotal for the child's socioemotional functioning, predicting later social competence (see Eisenberg, Hofer, Sulik, \& Spinrad, 2014, for a review). Through their engagement in positive activities, parents can play a major role in promoting the development of the child's self-regulatory system. Parent-child shared activities are unique opportunities for parents to provide their children with adaptive models of behavioral regulation, as well as to provide them with the necessary support for the internalization of self-control abilities (Thompson, 2014). Activities such as playing a new game, taking a walk in the park, or undertaking a new craft project, may hold significant emotional challenges for young children. By engaging in these activities parents may act as external regulators of children's emotions and behaviors, directly and indirectly intervene in their behavioral regulation process, namely by soothing distress and frustration, provoking positive emotion, shaping the children's interpretations of negatively experiences, and allaying the fears that may arise. These positive activities can also boost parent-child conversations that support children's understanding on the causes and consequences of their feelings, as well as their motivation and competence to accomplish self-regulated behavior.

Several studies have provided evidence for the role of parental engagement in promoting child self-control (Lindsey, Cremeens, Colwell, \& Caldera, 2009; Meece \& Robinson, 2014; Taylor, Eisenberg, Spinrad, \& Widaman, 2013). Most of these studies have focused on mothers, examining the relation between interactive dimensions of maternal engagement (e.g., dyadic synchrony and intrusiveness) and child self-control, with fathers' engagement receiving much less attention. Furthermore, these studies have mainly used brief observational assessments of the interactions between mothers and children. Despite their ability to clarify the interactive quality of parental engagement, these assessments are unable to capture the amount and type of engagement behaviors that fathers and mothers display over time. Understanding the amount of time parents invest on activities with children can be very important to clarify the ways parents influence the development of child self-control. Most of the studies addressing the benefits of high levels of parental involvement for children's social functioning have focused on parents' involvement in school, particularly through parent-teacher conferencing and participation in school activities (El Nokali, Bachman, \& Votruba-Drzal, 2010; Fantuzzo, Mcwayne, Perry, \& Childs, 2004). The contribution of parents' engagement in positive activities to children's social functioning has been less explored. Some studies reported negative associations between parental positive engagement and child externalizing child behavior problems (Siu, Ma, \& Chui, 2016; Vieira et al., 2016). In a study examining the association between fathers' involvement and preschoolers' social skills, Hosokawa, Katsura, and Shizawa (2015) found that the frequency of fathers' involvement in child rearing and playing activities with their children was positively associated with children's self-control. Very few studies have examined the influence of mothers' and fathers' engagement over time on children's social functioning (Lang et al., 2014). Lang et al. (2014) found the initial levels of mothers' engagement in positive activities and growth of fathers' engagement in positive activities during early infancy independently predicted child attention regulation and mastery motivation. Results from this study suggested the need for considering changes in the mean levels of mothers' and fathers' engagement over time to understand the acquisition of social-emotional outcomes during childhood. To our knowledge no previous study has examined the effects of mothers' and fathers' engagement over time on children's self-control. Also, the above studies were mainly focused on parental engagement during children's first year of life. Changes in parental engagement over time are important to address during later stages of early childhood, when parents' engagement in positive activities with the child can play a major role in fostering a number of significant developmental acquisitions, namely self-control abilities. In addition, differences between mothers' and fathers' engagement are particularly interesting to 
examine at this stage, as fathers are likely to spend more time with their children when they reach the preschool period than they did in early infancy (Meteyer \& Perry-Jenkins, 2010; Pleck, 1983; Wood \& Repetti, 2004).

\section{The Current Study}

The current study provides three major contributions for the available literature on parental engagement, specifically in activities that are likely to foster child development. First, change on both mothers' and fathers' engagement is examined during early childhood, particularly across the preschool period through first grade. Considering the evidence regarding changes in parental engagement in children's early ages is inconclusive (Lang et al., 2014; Meteyer \& Perry-Jenkins, 2010; Wood \& Repetti, 2004; Yeung et al., 2001), we explored all the possible directions in the change trajectories of parental engagement (increase, maintenance or decrease). Second, this study investigates whether variations in mothers' and fathers' WFC affect the change trajectories of their own and their partner's engagement with the child. Specifically, we examined the effect of mothers' conflict on both mothers' (actor effect) and fathers' (partner effect) engagement, as well as the effect of fathers' WFC on fathers' (actor effect) and mothers' (partner effect) engagement. By looking at WFC across 3-time points, our model is robust in detecting the impact of WFC on parental engagement over time. It is possible that WFC has a stable effect on parental engagement over time, but it is also possible that varying levels of WFC have a more time-specific effect on parental engagement. Results from previous studies suggested a negative impact of parents' WFC on distinct dimensions of parenting (Cinamon et al., 2007; Corwyn \& Bradley, 1999; Crouter, Bumpus, Maguire, \& McHale, 1999; Vieira et al., 2016). Based on this evidence, we anticipate that mothers' and fathers' WFC will explain individual differences on mothers' and fathers' engagement over time. Considering the interdependence between the two parents' work-family and parenting dynamics we also expected crossover effects of mothers' and fathers' WFC on their partners' parental engagement. Third, the current study investigates whether initial levels and change trajectories of mothers' and fathers' engagement predict children's self-control when controlling for time-varying WFC. Considering parents have an important role in promoting children's self-control (Feldman, Greenbaum, \& Yirmiya, 1999; Lindsey et al., 20098; Meece \& Robinson, 2014; Taylor et al., 2013), we hypothesize a positive link between mothers' and fathers' initial levels of engagement and children's self-control. In addition, we expect that positive changes in mothers' and fathers' engagement will increase levels of children's self-control.

\section{Method}

\section{Participants}

A sample of 156 children (67 girls; $M$ age $=48.02$ months, $S D=7.30)$, their mothers $\left(M_{\mathrm{age}}=34.87\right.$ years, $\left.S D=4.32\right)$, fathers $\left(M_{\text {age }}=36.19\right.$ years, $\left.S D=4.99\right)$, and preschool teachers $\left(n=68 ; M_{\text {age }}=39.07\right.$ years, $\left.S D=9.08\right)$ was recruited from 25 public and private preschool centers in the metropolitan area of Porto, Portugal. The average number of participating children per classroom was $3.47(S D=2.46)$. Portuguese preschool system includes children between 3 and 6 years of age. The vast majority of the Portuguese children enroll in private or public preschool age programs at age 3 , typically remaining with the same preschool teacher and peer group until elementary school. Participating children all came from families with dual-earner and cohabiting parents. Most of the participating families had one $(57 \%)$ or two $(39 \%)$ children $(M=1.49, S D=0.63)$ at $\mathrm{T} 1$ and $12 \%(n=19)$ of families increased the number of children during the course of the study. Nearly $12 \%$ of mothers $(n=19)$ and $23 \%$ of fathers $(n=36)$ completed primary education, $26 \%$ of mothers $(n=41)$ and $33 \%$ of fathers $(n=54)$ completed secondary education, whereas $62 \%$ of mothers $(n=96)$ and $44 \%$ of fathers $(n=68)$ had some form of higher education. The average number of working hours per week was $39.52(S D=7.78)$ for mothers and 44.99 $(S D=8.27)$ for fathers. Family monthly income ranged from less than $€ 1,100$ (11\%), €1,100-2,000 (45\%), €2,000-3,000 (30\%), to over $€ 3,000(14 \%)$. This sample is quite representative of the Portuguese dual-earner population, regarding family structure, parents' age range and working hours (INE, 2011). It includes however a large proportion of parents with higher education.

Data were obtained at three time points. Baseline assessment was conducted when children's average age was 48 months, ranging from 31 to 69 . These children were assessed annually for the following two years. Forty-four children (28\%) had missing data at $\mathrm{T} 2$, whereas six children had missing data at T3 (4\%). Attrition was mainly because parents and/or teachers refused to participate in some stage of the data collection. Logistic regression was conducted to examine the extent to which the absence of data at T2 and/or T3 was related to the demographic and study variables measured at T1. None of the demographic variables (i.e., family income, parents' age, number of children, education and number of work hours per week, child age and sex), nor the study variables (i.e., parental involvement, parents' WFC, and child self-control) was found to predict data loss at T2 and/or T3. In addition, Little's missing completely at random test indicated that missing data were consistent with the pattern of missing completely at random test $\left(\chi^{2}=307.49, p>.05\right)$.

\section{Measures}

Parental engagement was self-reported both by mothers and fathers, using the involvement subscale from the Parenting Relationship Questionnaire-Preschool Form (PRQ, Kamphaus \& Reynolds, 2006; Vieira, Cadima, Leal, \& Matos, 2013). This eight-item subscale taps parents' active participation in positive engagement activities, along with the parent's knowledge of the child's activities (e.g., "My child and I plan things to do together," "I teach my child how to play new games," "My child and I work on projects together," "My child and I take walks together," "My child and I do arts and crafts together"). Parents are asked to consider their current experience as a parent and to express their perspective on the different statements, using a 4-point Likert scale, ranging from 1 (never) to 4 (always).

Confirmatory factor analysis (CFA) was used to investigate whether these eight items load on a common factor representing parental engagement, and measurement invariance (MI) procedures (Vandenberg \& Lance, 2000) were conducted to examine the extent to which this factor structure remained invariant across 
time, as well as between mothers and fathers. Model fit was examined using the chi-square goodness-of-fit statistic, by considering chi-square to $d f$ ratio $\left(\chi^{2} / d f\right)$. Values less than 2 for this ratio are usually considered as an indicator of a "good" fit. Model fit was also evaluated through the root mean square error of approximation (RMSEA), the comparative fix index (CFI) and the standardized root-mean-square residual (SRMR). Values lower than .06 for RMSEA, greater than .95 for CFI, and lower than .08 for SRMR indicate good model fit (Hu \& Bentler, 1999; Schweizer, 2010).

CFA for the engagement measurement model revealed adequate fit for mothers at T1, T2, and T3 (see Table 1). The engagement's measurement model also revealed good fit to the fathers' data at T1, T2, and T3 (see Table 1). MI analysis indicated invariance of factor loadings across $\mathrm{T} 1, \mathrm{~T} 2$, and $\mathrm{T} 3$, both for mothers, $\Delta \chi^{2}(14)=20.53, p=.11, \Delta$ CFI $=.00$, and fathers, $\Delta \chi^{2}(14)=$ $11.04, p=.68, \Delta \mathrm{CFI}=.00$. MI of the engagement scale was also examined between parents. Results indicated invariance of factor loadings between mothers' and fathers' measures of engagement at $\mathrm{T} 1, \Delta \chi^{2}(7)=9.49, p=.22, \Delta \mathrm{CFI}=.00 ; \mathrm{T} 2, \Delta \chi^{2}(7)=7.59, p=$ $.37, \Delta$ CFI $=.00$; and T3, $\Delta \chi^{2}(7)=9.17, p=.24, \Delta$ CFI $=.00$. The Cronbach's alpha coefficients were .89 at $\mathrm{T} 1, .88$ at $\mathrm{T} 2$, and .90 at $\mathrm{T} 3$ for mothers, and .84 at T1, .87 at T2, and .84 at T3 for fathers.

WFC was assessed through an abbreviated version of Carlson, Kacmar, and Williams (2000) Work-Family Conflict Scale (WFCS, Vieira, Lopez, \& Matos, 2014). This six-item short scale measures the personal experiences regarding the interference from work to family (e.g., "I am often so emotionally drained when I get home from work that it prevents me from contributing to my family") and from family to work (e.g., "I have to miss work activities due to the amount of time I must spend on family responsibilities"). Each parent was asked to independently report his or her WFC. Items were rated using a 5-point Likert scale ranging from 1 (strongly disagree) to 5 (strongly agree). CFA

Table 1

Fit Indices of Hypothesized Measurement Models for the Whole Sample $(N=156)$

\begin{tabular}{lrrrrrr}
\hline \multicolumn{1}{c}{ Model } & $d f$ & \multicolumn{1}{c}{$\chi^{2}$} & $\chi^{2} / d f$ & CFI & RMSEA & SRMR \\
\hline Mother Eng. T1 & 17 & 23.47 & 1.38 & .99 & .05 & .03 \\
Mother Eng. T2 & 17 & $32.96^{*}$ & 1.94 & .96 & .09 & .04 \\
Mother Eng. T3 & 17 & 24.31 & 1.43 & .99 & .06 & .03 \\
Father Eng. T1 & 17 & $30.37^{*}$ & 1.79 & .97 & .07 & .04 \\
Father Eng. T2 & 17 & $29.52^{*}$ & 1.74 & .97 & .08 & .04 \\
Father Eng. T3 & 17 & 23.60 & 1.38 & .98 & .06 & .04 \\
Mother WFC T1 & 7 & 10.28 & 1.47 & .98 & .06 & .04 \\
Mother WFC T2 & 9 & 9.49 & 1.05 & 1.00 & .02 & .04 \\
Mother WFC T3 & 7 & 8.17 & 1.17 & .99 & .04 & .03 \\
Father WFC T1 & 7 & 10.06 & 1.44 & .98 & .05 & .05 \\
Father WFC T2 & 6 & 4.83 & .81 & 1.00 & .00 & .03 \\
Father WFC T3 & 7 & 7.77 & 1.11 & .99 & .03 & .03 \\
Child SC T1 & 12 & 20.03 & 1.38 & .99 & .06 & .04 \\
Child SC T3 & 10 & 13.89 & 1.67 & .99 & .07 & .03 \\
\hline
\end{tabular}

Note. $\mathrm{T} 1=$ first time of data collection; $\mathrm{T} 2=$ second time of data collection; $\mathrm{T} 3$ = third time of data collection; Eng. = engagement; $\mathrm{WFC}=$ work-family conflict; $\mathrm{SC}=$ self-control; $\mathrm{CFI}=$ comparative fit index; RMSEA $=$ root mean square of error of approximation; SRMR $=$ standardized root mean square.

$* p<.05$. revealed good model fit to mothers' data at $\mathrm{T} 1, \mathrm{~T} 2$, and $\mathrm{T} 3$, as well as to fathers' data at T1, T2, and T3 (see Table 1). MI procedures revealed invariance of factor loadings across T1, T2, and T3 for mothers, $\Delta \chi^{2}(10)=17.87, p=.06, \Delta \mathrm{CFI}=.01$, and fathers, $\Delta \chi^{2}(5)=7.09, p=.21, \Delta$ CFI $=-.00$. The Cronbach's alpha coefficients were .71 at $\mathrm{T} 1, .77$ at $\mathrm{T} 2$, and .69 at $\mathrm{T} 3$ for mothers and .63 at $\mathrm{T} 1, .72$ at $\mathrm{T} 2$, and .74 at $\mathrm{T} 3$ for fathers.

Children's self-control was measured at T1 and T3 using the Social Skills Rating System (Gresham \& Elliont, 1990). Seven items from the Self-Control subscale were used to measure teachers' perceptions of children's ability to control their behaviors in conflict (e.g., "controls temper when arguing with other children") and nonconflict situations (e.g., "waits turn in games or other activities"). Teachers were asked to rate on a 3-point scale ranging from 1 (never) to 3 (often) how characteristic each behavior was of a particular child, with higher scores indicating higher self-control. Construct validity was verified for the data at T1 and T3. Fit indices are listed in Table 1. MI analysis revealed invariance of factor loadings invariance between $\mathrm{T} 1$ and $\mathrm{T} 3, \Delta \chi^{2}(6)=11.72$, $p=.07, \Delta \mathrm{CFI}=.01$. For this study's sample, the Cronbach's alpha coefficients were .88 at $\mathrm{T} 1$ and .90 at $\mathrm{T} 3$.

\section{Procedure}

Data were collected within the scope of a broader longitudinal project aiming at understanding the impact of work-family dynamics on parenting and child development. Children, their parents, and preschool teacher were recruited at the beginning of school year. The study was explained to teachers and parents, after schools' board approval. Parents, school staff, and teachers signed written informed consents. The families' participation rate was $38 \%$. Data were collected 6 months after the beginning of school. Fathers, mothers and teachers completed annual questionnaires for 3 consecutive years. Parents reported on their involvement with their child and their WFC at T1, T2, and T3, whereas teachers reported on the child's self-control at $\mathrm{T} 1$ and $\mathrm{T} 3$.

\section{Data Analyses}

Analyses were conducted using composite scores on the study variables, namely parents' engagement, WFC, and children's selfcontrol. These scores were obtained by computing the mean of the items' scores for each measure. Descriptive statistics were then computed for demographic and study variables. Latent growth curve (LGC) analyses were conducted using structural equation modeling. A robust maximum likelihood estimation was applied to correct for non-normality and nonindependence of our data (some children were nested within preschool classrooms). Also, full information maximum likelihood estimation was used to avoid deleting subjects with missing data (Enders \& Bandalos, 2001). All analyses were conducted in R (R Core Team, 2013), using the "lavaan" package for Structural equation modeling (Rosseel, 2012).

To address the main research questions, a series of LGC models were specified and fitted to the data. Nested models were compared using the chi-square difference statistic. First, we tested an unconditional LGC model for parental engagement allowing within-time correlations between mothers' and fathers' engagement to account for the nonindependence of observations. Second, 
a conditional LGC of parental engagement, with WFC as timevarying covariate, was tested separately for mothers and fathers, evaluating whether individual differences in intercepts and slopes of parental engagement were explained by parents' own and their partner's perceptions of WFC over time. WFC was entered as a time-varying covariate assuming changes in parents' perception of WFC over time are unsystematic and nonlinear. Finally, we examined whether the intercepts and slopes of the previous conditional LGC models of parental engagement predicted child selfcontrol at T3, when controlling for child self-control at T1, child age and sex.

\section{Results}

Table 2 presents the correlations among the main study variables, as well as means and standard deviations. There was a positive association between child age and self-control at T1 $(r=$ $.21, p=.023)$. Compared to boys, girls were more likely to receive higher levels of maternal engagement at T2 $(r=.22, p=.023)$ and exhibit higher levels of self-control at T3 $(r=.22, p=.045)$. Child self-control at $\mathrm{T} 1$ was positively related to mother engagement at $\mathrm{T} 1(r=.22, p=.023)$ and $\mathrm{T} 2(r=.22, p=.041)$, as well as to child self-control at T3 $(r=.27, p=.006)$. Maternal engagement at T2 was positively linked to child self-control at T3 $(r=.21, p=.041)$. Child self-control at $\mathrm{T} 1$ was negatively associated with mothers' $(r=-.22, p=.022)$ and fathers' $(r=-.24, p=.013)$ WFC at T1 and fathers' WFC at T2 $(r=-.23, p=.027)$. As expected, there were strong associations between the reports of parental engagement over time, both for mothers and fathers. Also, there were concurrent negative associations between parents' WFC and parental engagement at all three time points. A series of hierarchical regression analyses was car- ried out to inspect the contributions of parents' working hours and number of children to parental engagement, when controlling for WFC. Parents' working hours and the number children did not significantly increase the proportion of variance explained by WFC, either in mothers' engagement at T1, $\Delta R^{2}=.018, \Delta F(2$, 146) $=1.471, p=.23 ; \mathrm{T} 2, \Delta R^{2}=.018, \Delta F(2,107)=1.016, p=$ .37 ; and T3, $\left.\Delta R^{2}=.023, \Delta F(2,128)=1.617, p=.20\right)$; or in fathers' engagement at T1, $\Delta R^{2}=.025, \Delta F(2,146)=2.043, p=$ $.13 ; \mathrm{T} 2, \Delta R^{2}=.026, \Delta F(2,107)=1.579, p=.21 ;$ and T3, $\Delta R^{2}=$ $.001, \Delta F(2,123)=0.064, p=.94$.

A model including two unconditional LGCs was tested to examine the trajectories of change in mothers' and fathers' engagement. Mothers' engagement and fathers' engagement were allowed to correlate within time to account for their nonindependence. Mothers' and fathers' initial level (intercept) and growth (slope) were allowed to correlate. This model with linear unconstrained growths (i.e., model with intercept and slope that were allowed to vary and unconstrained residual variances) for mothers' and fathers' engagement was compared with successively more constrained models. The final model (see Figure 1) estimated a mean latent intercept and slope for mothers' and fathers' engagement, $\chi^{2}(12)=$ $16.97, p=.151, \chi^{2} / d f=1.41$, CFI $=.98$, RMSEA $=.05$, SRMR $=.08$. This model constrained the correlations between mothers' and fathers' engagement at T1, T2, and T3 to be equal. Nonsignificant paths, namely the correlations between the slope of mother's engagement with the remaining latent constructs, were trimmed to obtain the most parsimonious model (Bentler \& Mooijaart, 1989). No differences were found between the final and the unconstrained model, $\Delta \chi^{2}(6)=10.23, p=.115$. As depicted in Figure 1, the within-time correlations between mothers' and fathers' engagement were significant at $\mathrm{T} 1(r=.22, p=.035), \mathrm{T} 2$

Table 2

Pearson Correlations and Descriptive Statistics for the Main Study Variables $(N=156)$

\begin{tabular}{|c|c|c|c|c|c|c|c|c|c|c|c|c|c|c|c|c|}
\hline Variable & 1 & 2 & 3 & 4 & 5 & 6 & 7 & 8 & 9 & 10 & 11 & 12 & 13 & 14 & 15 & 16 \\
\hline \multicolumn{17}{|l|}{$\mathrm{T} 1$} \\
\hline 1. Child age (months) & - & & & & & & & & & & & & & & & \\
\hline 2. Child sex (female) & -.06 & - & & & & & & & & & & & & & & \\
\hline 3. Child SC & $.21^{*}$ & .10 & - & & & & & & & & & & & & & \\
\hline 4. Mother Eng. & -.09 & .11 & $.22 *$ & - & & & & & & & & & & & & \\
\hline 5. Father Eng. & .13 & -.08 & .04 & $.18^{*}$ & - & & & & & & & & & & & \\
\hline 6. Mother WFC & -.02 & .16 & $-.22^{*}$ & $-.26^{* *}$ & -.10 & - & & & & & & & & & & \\
\hline 7. Father WFC & -.11 & .06 & $-.24^{*}$ & -.09 & $-.27^{* * *}$ & $.34^{* *}$ & - & & & & & & & & & \\
\hline \multicolumn{17}{|l|}{$\mathrm{T} 2$} \\
\hline 8. Mother Eng. & -.02 & $.22 *$ & $.22^{*}$ & $.65^{* *}$ & .13 & $-.21^{*}$ & -.01 & - & & & & & & & & \\
\hline 9. Father Eng. & -.00 & .00 & .00 & $.39^{* * *}$ & $.66^{\text {*** }}$ & -.08 & -.19 & $.37^{* *}$ & - & & & & & & & \\
\hline 10. Mother WFC & .14 & .00 & -.10 & $-.20^{*}$ & -.13 & $.44^{* *}$ & $.26^{\text {*** }}$ & $-.21^{*}$ & -.16 & - & & & & & & \\
\hline 11. Father WFC & .04 & .04 & $-.23^{*}$ & $-.28^{* *}$ & -.13 & .17 & $.43^{* *}$ & $-.23^{*}$ & $-.28^{* *}$ & $.35^{* * *}$ & - & & & & & \\
\hline \multicolumn{17}{|l|}{$\mathrm{T} 3$} \\
\hline 12. Child SC & -.03 & $.17^{*}$ & $.27^{* *}$ & .05 & -.03 & -.04 & -.02 & $.21^{*}$ & .00 & .11 & -.17 & - & & & & \\
\hline 13. Mother Eng. & -.11 & .17 & .13 & $.54^{* *}$ & .05 & -.13 & -.01 & $.61^{* *}$ & $.27^{* * *}$ & .01 & -.12 & .08 & - & & & \\
\hline 14. Father Eng. & .07 & -.03 & .10 & $.20^{*}$ & $.59^{* *}$ & -.11 & -.10 & 20 & $.51^{* * *}$ & -.03 & -.18 & .07 & .10 & - & & \\
\hline 15. Mother WFC & .01 & .09 & -.10 & -.10 & -.07 & $.54^{* * *}$ & $.22^{*}$ & -.19 & -.09 & $.38^{* * *}$ & $.21^{*}$ & .08 & $-.20^{*}$ & -.04 & - & \\
\hline 16. Father WFC & -.10 & .12 & -.18 & -.07 & $-.27^{* * *}$ & .12 & $.48^{* *}$ & -.04 & $-.24^{*}$ & $.24^{*}$ & $.58^{* *}$ & -.07 & -.04 & $-.25^{\text {*** }}$ & $.30^{* * *}$ & - \\
\hline$M$ & 48.02 & .48 & 1.48 & 2.91 & 2.71 & 2.49 & 2.55 & 2.92 & 2.77 & 2.40 & 2.50 & 1.53 & 2.87 & 2.83 & 2.42 & 2.47 \\
\hline$S D$ & 7.30 & .50 & .43 & .53 & .44 & .64 & .58 & .49 & .47 & .71 & .64 & .49 & .54 & .43 & .64 & .68 \\
\hline Range & $31-69$ & - & $.0-2.0$ & $1.9-4.0$ & $1.8-4.0$ & $1.0-4.5$ & $1.0-4.5$ & $1.9-4.0$ & $1.9-4.0$ & $1.0-4.0$ & $1.0-4.3$ & .0-2.0 & $1.8-4.0$ & $1.8-3.9$ & $1.0-4.0$ & $1.0-4.7$ \\
\hline
\end{tabular}

Note. $\mathrm{T} 1=$ first time of data collection; $\mathrm{T} 2=$ second time of data collection; $\mathrm{T} 3=$ third time of data collection; $\mathrm{SC}=$ self-control; Eng. $=$ engagement; $\mathrm{WFC}=$ work-family conflict.

${ }^{*} p<.05 .{ }^{* * *} p<.01$. 


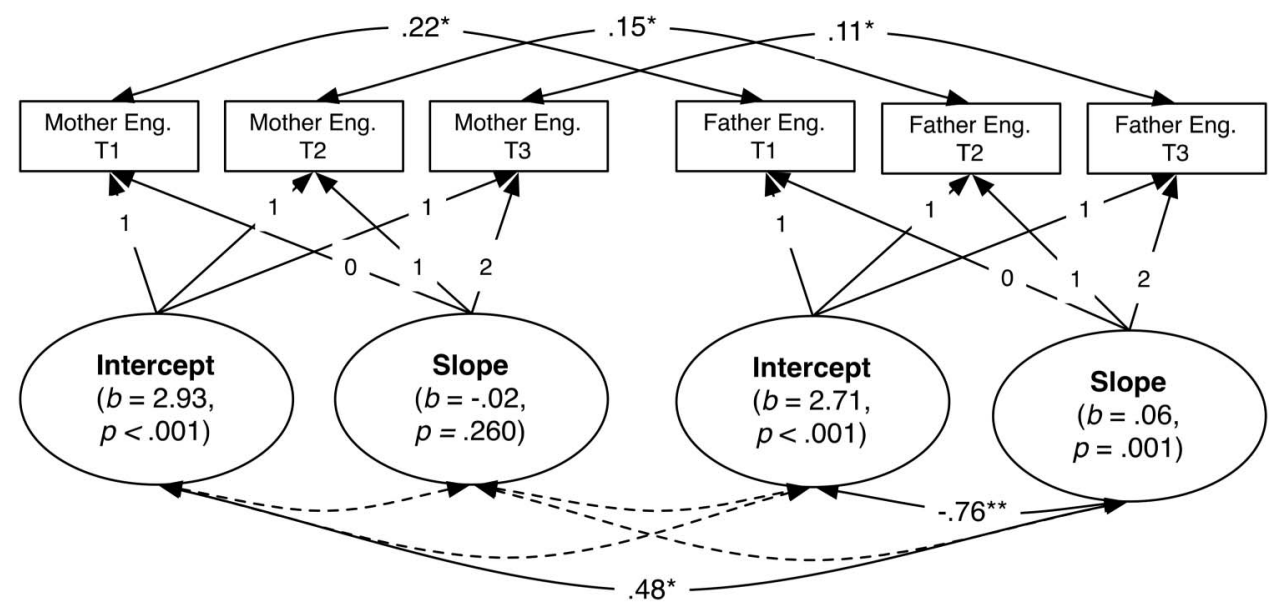

Figure 1. Structural equation model examining unconditional latent growth curves for mothers' and fathers' engagement. Standardized coefficients are presented; dashed lines represent trimmed paths; Eng. = Engagement; $\mathrm{T} 1=$ Time $1 ; \mathrm{T} 2=$ Time $2 ; \mathrm{T} 3=$ Time $3 .{ }^{*} p<.05 .{ }^{* *} p<.01$.

$(r=.15, p=.035)$, and T3 $(r=-11, p=.035)$. The mean intercept for mothers' engagement was $2.93(p<.001,95 \%$ confidence interval CI $[2.85,3.01])$, whereas the mean slope was nonsignificant $(b=-.03, p=.260,95 \%$ CI $[-.07, .02])$. On average, fathers reported a mean score of $2.71(p<.001,95 \%$ CI $[2.64,2.78])$ on parental engagement at $\mathrm{T} 1$, followed by a positive linear slope $(b=.06, p=.001,95 \% \mathrm{CI}[.02, .09])$; these parameters were both significantly different from 0 . Wald-test revealed mother's initial levels (intercept) of engagement to be significantly higher than father's initial levels of engagement, $\chi^{2}(1)=18.75$, $p<.001$. Compared to mothers, fathers showed significantly higher growth (slope) in parental engagement, $\chi^{2}(1)=9.07, p=$ .003 . The variances of both intercepts for mothers' engagement $(b=.15, p<.001,95 \%$ CI $[.11, .19])$ and for fathers' engagement $(b=.16, p<.001,95 \%$ CI $[.11, .20])$ were significant, suggesting significant individual variation on both mothers' and fathers' initial levels of engagement. Slope variance was nonsignificant for mothers' $(b=.00, p=.795,95 \%$ CI $[-.02, .02])$ and fathers' engagement $(b=.00, p=.792,95 \%$ CI $[-.02, .03])$, suggesting similar individual paths of stability and growth for mothers and fathers, respectively. Fathers' growth of engagement was positively associated with mothers' initial levels of engagement ( $r=$ $.46, p=.014$ ) and negatively associated with father's initial levels of engagement $(r=-.76, p>.001)$.

The influence of WFC on parental engagement was examined by fitting a conditional LGC model of parental engagement, with WFC as time-varying covariate. This model was tested independently for mothers and fathers due to restrictions on sample size but included in each model both mother's and father's WFC. By including WFC as a time-varying covariate it was assumed that parents' perceptions of WFC might be subject to unsystematic variations over time. Time-varying effects of WFC on parental engagement were specified by regressing parental engagement on actor and partner concurrent values of WFC (e.g., parental engagement at T1 regressing both on mother's and father's WFC at T1). This conditional LGC model of parental involvement was compared with a model in which actor and partner effects of WFC on parental involvement were constrained to zero. The former model revealed better fit, both for mothers, $\Delta \chi^{2}(6)=17.67, p=.007$, and fathers, $\Delta \chi^{2}(6)=8.92, p<.001$. To examine the stability of the associations between parental WFC and engagement, a conditional LGC model of parental engagement in which actor and partner concurrent effects of WFC were allowed to vary over time was compared to a similar nested model in which the concurrent effects of WFC on parental engagement were constrained to be equal across T1, T2, and T3. There were no significant differences in these two models, either for mothers, $\Delta \chi^{2}(4)=1.17, p=.883$, or for fathers, $\Delta \chi^{2}(4)=1.49, p=.828$. Partner effects of WFC on mothers' and fathers' engagement were nonsignificant across time and they were trimmed for parsimony reasons (Bentler \& Mooijaart, 1989). There were no significant differences of fit between the initial model and the trimmed model, both for mothers, $\Delta \chi^{2}(1)=0.33, p=.564$, and fathers, $\Delta \chi^{2}(1)=2.45, p=.118$. Based on these results, partner effects were excluded from subsequent models in this study.

Figure 2 shows final conditional LGC models with WFC as time-varying covariate, both for mothers' (Model A) and fathers' (Model B) engagement. The conditional LGC model provided very good fit to the mothers' data, $\chi^{2}(23)=18.63, p=.722, \chi^{2} / d f=$ $0.81, \mathrm{CFI}=1.00, \mathrm{RMSEA}=.00, \mathrm{SRMR}=.05$. Although there was a decrease in the intercept variance from the unconditional ( $b=.18, p<.001,95 \%$ CI $[.12, .24])$ to the conditional model ( $b=.14, p<.001,95 \%$ CI $[.10, .18])$, this parameter was still significantly different from zero. Mean slope variance remained nonsignificant $(b=.00, p=.805,95 \%$ CI $[-.02, .01])$. Regarding the time-varying covariate, there was a significant negative effect of WFC on mothers' engagement rates, stable across T1 $(b=-.15, p<.001,95 \%$ CI $[-.23,-.07], \beta=-.19), \mathrm{T} 2$ $(b=-.15, p<.001,95 \% \mathrm{CI}[-.23,-.07], \beta=-.22)$, and T3 $(b=-.15, p<.001,95 \%$ CI $[-.23,-.07], \beta=-.18)$. The conditional LGC model also yielded good fit to fathers' data, $\chi^{2}(13)=8.37, p=.819, \chi^{2} / d f=0.64, \mathrm{CFI}=1.00$, RMSEA $=$ $.00, \mathrm{SRMR}=.03$. The individual variance of the intercept has increased from the unconditional $(b=.11, p<.001,95 \%$ CI [.07, $.15])$ to the conditional model ( $b=.15, p<.001,95 \%$ CI [.11, $.19])$, whereas the slope's variance remained nonsignificant ( $b=$ 

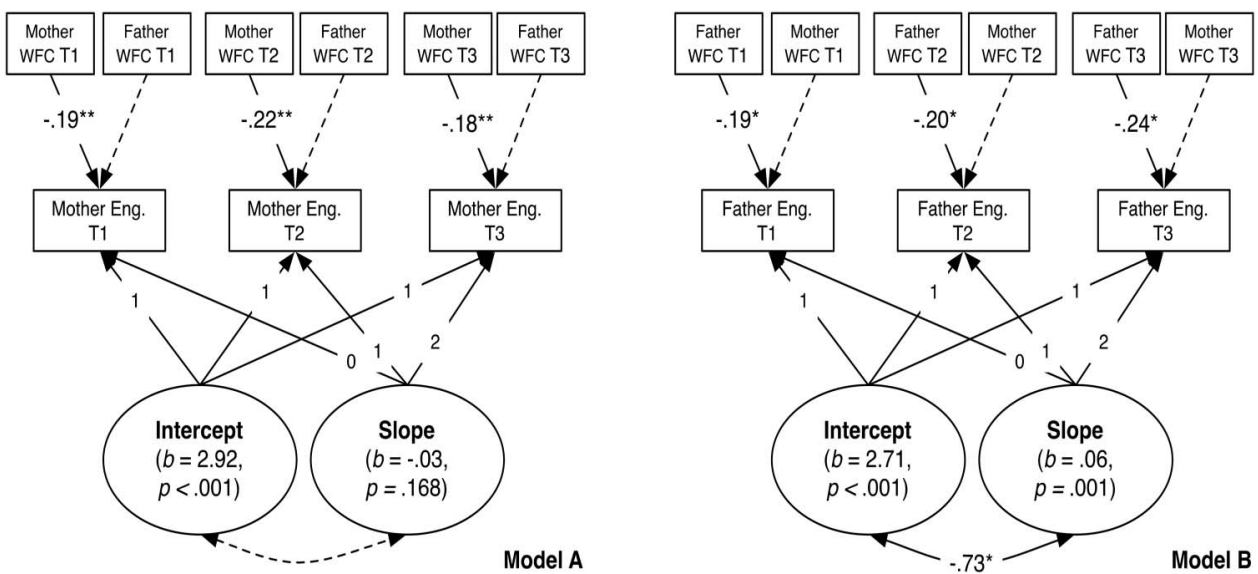

Figure 2. Structural equation models examining conditional latent growth curves for mothers' (Model A) and fathers' (Model B) engagement with actor and partner work-family conflict as time-varying covariates. Standardized coefficients are presented; dashed lines represent trimmed paths; WFC $=$ work-family conflict; Eng. = engagement; $\mathrm{T} 1=$ Time $1 ; \mathrm{T} 2=$ Time $2 ; \mathrm{T} 3=$ Time $3 .{ }^{*} p<.05 .{ }^{* *} p<.01$.

$.00, p=.734,95 \%$ CI $[-.02, .03])$. As for mothers, fathers' WFC negatively affected their parental engagement at $\mathrm{T} 1(b=-.15$, $p=.029,95 \%$ CI $[-.28,-.02], \beta=-.19), \mathrm{T} 2(b=-.15, p=$ $.029,95 \%$ CI $[-.28,-.02], \beta=-.20)$, and T3 $(b=-.15, p=$ $.029,95 \%$ CI $[-.28,-.02], \beta=-.24)$.

Child self-control at T3 was added as an outcome variable to both mothers' and fathers' LGC models. This allowed for estimating whether the initial level and growth rate of parental engagement predicted child self-control at T3, when controlling for child age, gender and self-control at T1. The nonsignificant effects of child age and gender on self-control were trimmed for parsimony reasons (Bentler \& Mooijaart, 1989). There were no significant differences between the overall fit of the initial and trimmed model, both for mothers, $\Delta \chi^{2}(2)=2.73, p=.26$, and fathers, $\Delta \chi^{2}(2)=3.61, p=.17$. Figure 3 provides standardized regression weights for both mothers' (Model A) and fathers' (Model B) trimmed models. Model fit was good for mothers, $\chi^{2}(28)=40.26$, $p=.063, \chi^{2} / d f=1.45, \mathrm{CFI}=.92, \mathrm{RMSEA}=.05, \mathrm{SRMR}=.08$,
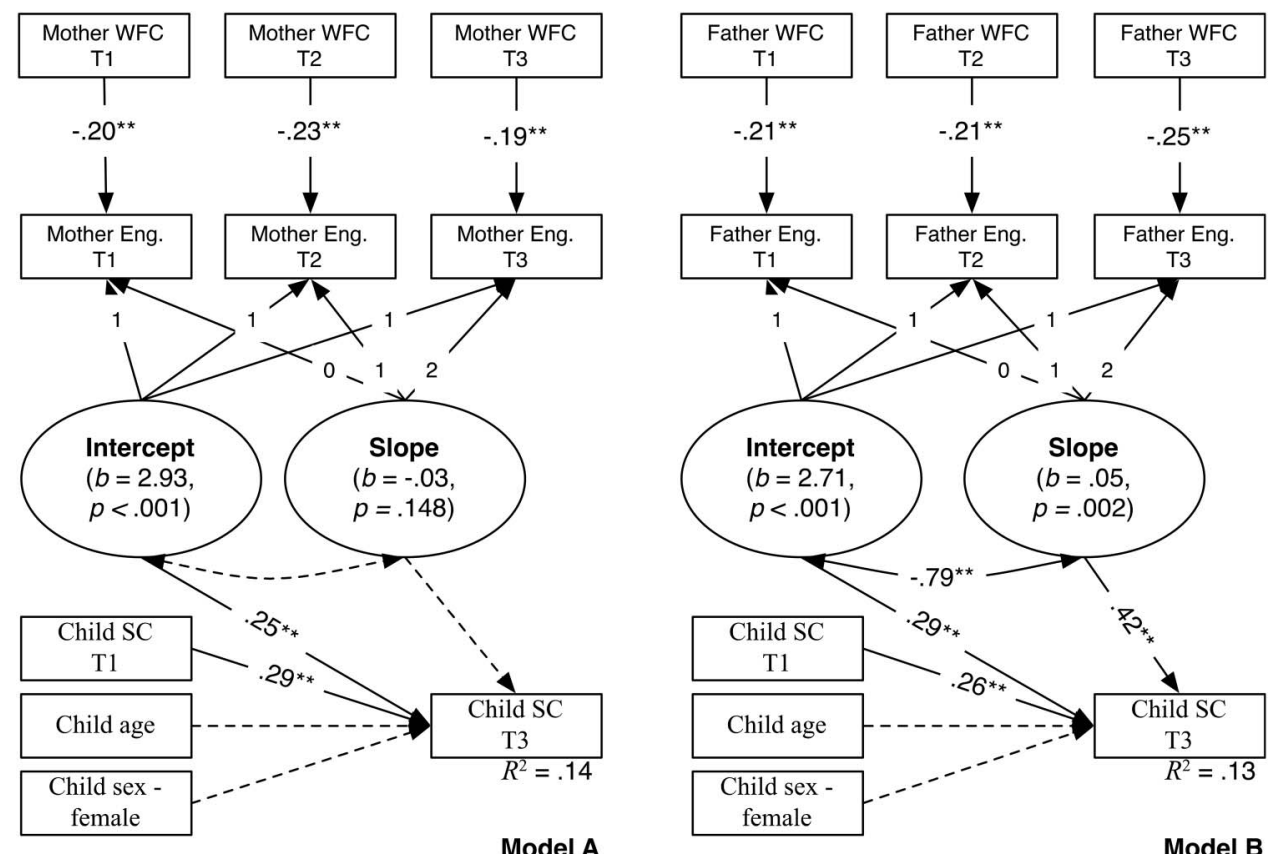

Figure 3. Structural equation models examining the effects of mothers' (Model A) and fathers' (Model B) engagement on child self-control. Standardized coefficients are presented; dashed lines represent trimmed paths; $\mathrm{WFC}=$ work-family conflict; Eng. $=$ engagement; $\mathrm{T} 1=$ Time $1 ; \mathrm{T} 2=$ Time 2 ; $\mathrm{T} 3=$ Time $3 .{ }^{*} p<.05$. *** $p<.01$. 
and fathers, $\chi^{2}(26)=17.91, p=.88, \chi^{2} / d f=0.69, \mathrm{CFI}=1.00$, RMSEA $=.00$, SRMR $=.04$. For mothers, the initial levels of engagement (intercept) had a positive effect on child self-control ( $b=.35, p<.001,95 \%$ CI $[.22, .47], \beta=.25)$. Both the intercept $(b=.37, p<.001,95 \%$ CI $[.25, .47], \beta=.29)$ and slope $(b=$ $2.06, p<.001,95 \%$ CI [.99, 3.12], $\beta=.42$ ) of fathers' engagement positively predicted child self-control at T3 (see Figure 3, Model B). There was a significant negative association between fathers' intercept and slope of engagement $(b=-.03, p<.001$, $95 \%$ CI $[-.05, .16], \beta=-.79)$. The LGC models of mothers' and fathers' engagement explained $14 \%$ and $13 \%$ of variance in child self-control, respectively.

\section{Discussion}

Parents are a central social context for human development, ultimately affecting most of the relevant developmental acquisitions across the life span. Particularly in early ages, children's social world is highly condensed around their parents. This reinforces the importance of parents' engagement as a way to promote children's development. Through their engagement in positive and progressively more complex social interactions with their children, parents are creating conditions for children's development across a wide range of domains, including socioemotional development. However, parental engagement may also be susceptible to the influences of social contexts, such as the mesosystem established between work and family. This article focuses on the trajectories of parental engagement in early childhood, specifically from preschool to first grade. In the current study we examined whether parents' engagement was influenced by parents' WFC and if changes in mothers' and fathers' engagement predicted child selfcontrol. This work yielded three major findings. First, mothers and fathers were found to display significant differences in their trajectories of parental engagement; mothers showed higher initial levels of engagement than fathers, whereas fathers demonstrated a significant linear growth on their parental engagement. Second, parental WFC relates negatively to parental engagement; this trend was continuously observed across time, on both mothers and fathers, although partners' effects were not found. Third, the initial levels of both mothers' and fathers' engagement, as well as fathers' growth rate of parental engagement predicted child selfcontrol, taking into consideration the link between WFC and parental engagement across time.

This study assumes parental engagement as a dynamic dimension of parenting that is susceptible to changes over time and is one of the few to establish this growth. In fact, very few prior works have addressed changes in parental engagement over time (Lang et al., 2014; Meteyer \& Perry-Jenkins, 2010; Wood \& Repetti, 2004). The available research seems to agree that both, mothers and fathers, display increasing levels of parental engagement over the child's first year of life (Lang et al., 2014; Meteyer \& PerryJenkins, 2010). During middle childhood, Wood and Repetti (2004) reported differences between mothers and fathers in their global involvement; fathers showed increasing levels of involvement while mothers tended to display a decreasing involvement over time. To our knowledge, the current study is one of the first attempts to understand variations on mothers' and fathers' engagement with children from 4 to 6-year-old, specifically in activities that are likely to foster child development. Children at these ages may considerably benefit from spending time with their parents in activities such as play, outdoor activities and arts. Parents' engagement in intensive parent-child interactions may contribute to children's cognitive and socioemotional development (Amato \& Rivera, 1999; Cabrera et al., 2007; Lang et al., 2014). The current study adds to the understanding of parental engagement over time (Lang et al., 2014; Meteyer \& Perry-Jenkins, 2010; Wood \& Repetti, 2004) by pointing out significant differences in the initial levels and growth rates of engagement between mothers and fathers. Our results showed that mothers have higher initial levels of engagement than fathers. Mothers have stable levels of engagement over time, whereas fathers displayed a significant growth in their engagement over time. It seems that mothers tend to consistently display high levels of engagement over the preschool period. Although fathers showed lower starting levels of engagement than mothers, their estimated growth suggests an approximation to mothers' levels of parental engagement over time. This approximation may be related to the increasing emphasis acquired during the preschool period by the play/companionship component on parent-child interactions, which has been considered a salient component of fathers' engagement (Yeung et al., 2001). It is also possible that fathers' engagement increased because children tend to be more active in requesting their fathers' participation in play activities. Most notably, this is the first study to our knowledge to analyze the changes in mothers' and fathers' parental engagement, while controlling for their nonindependence. Results showed concurrent positive associations between mothers' and fathers' engagement. In addition, we found a positive association between mothers' initial levels of engagement and fathers' growth of engagement and a negative association between fathers' initial levels and growth rates of engagement. These findings overcome an important limitation from previous studies, suggesting that children with mothers showing higher initial levels of engagement and fathers showing lower initial levels of engagement may experience higher growth rates in their fathers' engagement. Our findings are consistent with previous literature which has noted that mothers and fathers are progressively balancing their rates of involvement, particularly in positive engagement activities (McBride \& Mills, 1993; Yeung et al., 2001). These trends ought to be particularly manifest in dual-earner families, where mothers and fathers must have more balanced and interdependent levels of paternal engagement to complement each other's availability to provide children with positive engagement activities (Crouter et al., 1987; Gottfried et al., 2002; Zick et al., 2001). The nonsignificant correlations between mothers' slope and the remaining latent constructs (mothers' intercept, fathers' intercept, and slope) can be explained by the lack of mean change and variability in mothers' slope of engagement. Future studies using a more diverse sample of mothers might provide further clarification on the links mothers' and fathers' growth rates of parental engagement.

Our results contribute to an increasing understanding of how work-family dynamics may impact variations on mothers' and fathers' engagement over time. Parents from dual-earner families deal with specific challenges concerning the balance between job demands and parental tasks (Bonney et al., 1999; DannerVlaardingerbroek et al., 2013; Meteyer \& Perry-Jenkins, 2010; Zick et al., 2001). Previous research suggests that parents' ability to integrate work and family demands is an important positive predictor for distinct parenting dimensions, namely parents' psy- 
chological availability, parental self- efficacy, and the quality of parent-child interactions (Matias et al., 2017; Cinamon et al., 2007; Corwyn \& Bradley, 1999; Crouter et al., 1999; Vieira et al., 2016). Nonetheless, these studies have either been cross-sectional studies or have not focused on the effects of parents' WFC on parental engagement over time. In this study we examined the effects of parents' WFC on the trajectories of parental engagement, assuming that the parents' levels of WFC may change over time. We also investigated whether the effects of parents' WFC on their parental engagement were longitudinally stable. We found parents' individual perceptions of WFC were negatively linked to their own levels of parental engagement. The negative effect of WFC on parental engagement was found to be consistent across time, both for mothers and fathers. Our results did not support the existence of crossover effects of mothers' and fathers' WFC on their partners' engagement. It seems that parents adopt different levels of parental engagement regardless their partners' WFC. The absence of these effects may be explained by the relative high levels of engagement and by the fact that in our sample both mothers and fathers have a full time working schedule. The less adequate internal consistency of WFC scores, namely for mothers at T3 and for fathers at T1, may have conditioned the identification of partner effects. Future studies may consider using the full version of the WFC scale (Carlson et al., 2000) as a way to achieve more reliable scores of WFC. Also, a more fine-grained assessment of daily routines could perhaps better capture the oscillations and compensatory mechanisms in work-family dynamics and parental engagement. Despite the absence of crossover effects, our findings confirm the linkage between work and parenting dynamics suggested in previous research (Cinamon et al., 2007; Corwyn \& Bradley, 1999; Vieira et al., 2016) and extend this prior research by suggesting a stable negative relation between parents' WFC and their ability to maintain high levels of participation in positive engagement activities with the child. These findings illustrate how parental employment exosystem may influence family microsystem (Bronfenbrenner \& Morris, 2006). According to Bronfenbrenner's perspective (Bronfenbrenner \& Morris, 2006), the exosystem refers to the interplay between two or more settings, at least one of which does not contain the developing person. Findings from the current study highlight indirect influence of parent's work exosystem on the child's proximal processes taking place within the family environment. It seems that parents who experience high levels of WFC are less likely to engage in activities that may stimulate children's development. Although we found WFC was a significant predictor for parents' engagement over time, the variance in mothers' and fathers' initial levels of engagement remained significant after including WFC as a time-varying covariate. This finding indicates the need to consider additional variables that might explain why parents display distinct starting levels of parental engagement. Future works might focus on examining these other potential sources of individual variability for parental engagement, namely at the child (e.g., temperament) and parents (e.g., education level, the interaction between working hours and work-related stressors and parents' cognitive-emotional strategies) levels.

An important contribution of the current study was to clarify whether changes in parental engagement over time predicted children's acquisitions of behavioral self-control. Children's ability to regulate their own behavior in social interactions is a crucial developmental acquisition that predicts later social adjustment and competence (Eisenberg et al., 2014; Shonkoff \& Phillips, 2000). Several studies have pointed out the important role of the interactive quality of parental engagement in promoting children's selfcontrol (Feldman et al., 1999; Lindsey et al., 2009; Meece \& Robinson, 2014; Taylor et al., 2013). However, most studies addressing the influence of parental involvement on children's socioemotional functioning have focused on parental involvement in school-based activities, including parents' participation in school activities, parent-teacher conferencing and promoting children's learnings at home (El Nokali et al., 2010; Fantuzzo et al., 2004; Rimm-Kaufman, Pianta, Cox, \& Bradley, 2003). To our knowledge, no prior study investigated whether parents' rates of engagement in positive engagement activities across the early childhood period affect the child's self-control, when controlling for stability of self-control. Unlike previous works, the current study focused on parental participation in positive engagement activities, characterized by intensive and positive parent-child interactions (Pleck, 2010). We found both mothers' and fathers' initial levels of engagement affect child self-control. These results suggest that higher initial levels of parental engagement at 48 months, as reported by parents, predict better outcomes for children's self-control, as reported by teachers. Results also showed that increases in paternal engagement over time are related to higher teacher-rated self-control at 72 months. It appears that the growth of paternal behavior during the preschool period and early elementary school has a positive influence on children's later self-control abilities. These findings are consistent with those of Lang at al. (2014) who found that what best predicted children's social competence (i.e., attention regulation and mastery motivation) were the initial levels of engagement for mothers and the increases in positive engagement for fathers. Besides providing evidence for the influence of mothers' initial levels and fathers' growth of engagement on child self-control, the current study also indicates that children with highly engaged fathers at 48 months are more likely to display higher self-control than children with fathers who reported lower initial levels of engagement. The failure to find a connection between growth of maternal engagement and child self-control was probably due to the absence of a significant growth in mothers' engagement during this time period. Mothers reported stable levels of engagement over time preventing the identification of effects between changes in maternal engagement and child self-control. Participating mothers came from dualearner families, most of them held full-time jobs across the entire study period. Perhaps future studies including families with different work arrangements may offer the opportunity to observe changes in maternal engagement over time and to clarify whether these changes have consequences for children's self-control.

The current study provides evidence for the benefits of high parental engagement for young children's development of selfcontrol. As argued by Bronfenbrenner and Morris (2006), the effectiveness of a certain activity for promoting development depends on whether it occurs regularly for a meaningful period of time. Thus, occasional and interrupted parent-child activities may be ineffective at fostering children's developmental acquisitions. Our findings are consistent with this preposition suggesting that parents may foster children's self-control by maintaining high levels of participation in positive engagement activities over time. We found constant high levels of maternal engagement and in- 
creasing levels of paternal engagement over time predict children's ability to control emotions and behavior in social contexts.

To our knowledge, this is the first study to examine the trajectories of parental engagement in the early childhood period in mothers and fathers from dual-earner families and to clarify their influence on children's self-control. Several limitations from prior studies were overcome namely by including longitudinal data on maternal and paternal engagement and by testing the effects of parental engagement on children's self-control while controlling for prior levels of self-control. For this study, parental engagement was documented through parents' report whereas teachers reported on children's self-control. This is also an improvement over previous studies that used parents to report both parental engagement and children's outcomes. Despite its noteworthy strengths, this study has some limitations that must be acknowledged. Results were based on data from children and parents from dual-earner families, restricting generalization to children and parents from other family configurations. Balancing work and family demands and their effects on parental engagement across time may be particularly challenging in single-parent families. Our findings might also not apply to same-sex couples with children. Finally, it may be possible that the trajectories of engagement over time are different between parents in dual- and single-earner families. The current study examined growth of parental engagement in dualearner families, accommodating the dependent nature of mothers' and fathers' data. The results offer valuable evidence regarding the influence of parental engagement over time on the acquisition of children's self-control in early childhood, suggesting mothers' and fathers' levels of engagement over time affect children's selfcontrol. However no conclusions on the shared and nonshared contributions of mothers' and fathers' engagement to children's self-control can be made, as the effects of mothers' and fathers' engagement on children's self-control were examined in separate models. Further investigation is needed to clarify the relative contribution of both parents' engagement to children's self-control and to understand the interaction between mothers' and fathers' engagement across time. In addition, there is a need for more research on the bidirectional influences among child self-control, parental engagement and parents' WFC across time. Finally, the current study focused on parents' amount of participation in positive engagement activities with their children. Further research may expand our findings by examining whether children's acquisition of self-control abilities is influenced both by the amount of parental participation in positive activities and by the quality of parent-child interactions during these positive engagement activities on children's self-control abilities. Beyond these recommendations for future research, the present study has also implications for practice and policy. Our findings may provide some directions for the efforts of early childhood practitioners to promote children's self-control. Practitioners may focus on enhancing mothers' and fathers' participation in positive engagement activities, such as shared play and physical outdoor activities. Because these are usually unscripted and child-oriented activities, children may experience several behavior challenges while parents provide emotional safety and support to children's self-regulatory efforts. Through their active participation in positive engagement activities, parents may provide children with adaptive behavioral models and support children's development of self-control abilities. The negative connection between WFC and parental engagement con- firmed in this study may also serve policymakers who seek to implement effective programs for preserve both parents' participation in positive engagement activities despite the difficult balance between work and family demands.

\section{References}

Amato, P., \& Rivera, F. (1999). Paternal involvement and children's behavior problems. Journal of Marriage and the Family, 61, 375-384. http://dx.doi.org/10.2307/353755

Bentler, P. M., \& Mooijaart, A. (1989). Choice of structural model via parsimony: A rationale based on precision. Psychological Bulletin, 106, 315-317. http://dx.doi.org/10.1037/0033-2909.106.2.315

Bianchi, S. M. (2000). Maternal employment and time with children: Dramatic change or surprising continuity? Demography, 37, 401-414. http://dx.doi.org/10.1353/dem.2000.0001

Bonney, J., Kelley, M., \& Levant, R. (1999). A model of fathers' behavioural involvement in child care in dual-earner families. Journal of Family Psychology, 13, 401-415. http://dx.doi.org/10.1037/0893-3200 13.3.401

Bronfenbrenner, U., \& Morris, P. (2006). The bioecological model of human development. In W. Damon \& R. Lerner (Eds.), Handbook of child psychology: Vol. 1. Theoretical models of human development (6th ed., pp. 793-828). Hoboken, NJ: Wiley.

Cabrera, N., Shannon, J., \& Tamis-LeMonda, C. (2007). Fathers' influence on their children's cognitive and emotional development: From toddlers to pre-K. Applied Developmental Science, 11, 208-213. http://dx.doi .org/10.1080/10888690701762100

Carlson, D., Kacmar, K., \& Williams, L. (2000). Construction and initial validation of a multidimensional measure of work-family conflict. Journal of Vocational Behavior, 56, 249-276. http://dx.doi.org/10.1006/jvbe .1999 .1713

Casper, W. J., Eby, L. T., Bordeaux, C., Lockwood, A., \& Lambert, D. (2007). A review of research methods in IO/OB work-family research. Journal of Applied Psychology, 92, 28-43. http://dx.doi.org/10.1037/ 0021-9010.92.1.28

Cinamon, R., Weisel, A., \& Tzuk, K. (2007). Work-family conflict within the family: Conssover effects, perceived parent-child interaction quality, parental self-efficacy, and life role attributions. Journal of Career Development, 34, 79-100. http://dx.doi.org/10.1177/0894845307304066

Cooklin, A. R., Dinh, H., Strazdins, L., Westrupp, E., Leach, L. S., \& Nicholson, J. M. (2016). Change and stability in work-family conflict and mothers' and fathers' mental health: Longitudinal evidence from an Australian cohort. Social Science \& Medicine, 155, 24-34. http://dx.doi .org/10.1016/j.socscimed.2016.02.036

Corwyn, R., \& Bradley, R. (1999). Determinants of paternal and maternal investment in children. Infant Mental Health Journal, 20, 238-256.

Crouter, A., Bumpus, M., Maguire, M., \& McHale, S. (1999). Linking parents' work pressure and adolescents' well-being: Insights into dynamics in dual-earner families. Developmental Psychology, 35, 14531461. http://dx.doi.org/10.1037/0012-1649.35.6.1453

Crouter, A., Perry-Jenkins, M., Huston, T., \& McHale, S. (1987). Processes underlying father involvement in dual-earner and single-earner families. Developmental Psychology, 23, 431-440. http://dx.doi.org/10.1037/ 0012-1649.23.3.431

Danner-Vlaardingerbroek, G., Kluwer, E., van Steenbergen, E., \& van der Lippe, T. (2013). The psychological availability of dual-earner parents for their children after work. Family Relations: An Interdisciplinary Journal of Applied Family Studies, 62, 741-754. http://dx.doi.org/10 1111/fare.12039

Eisenberg, N., Hofer, C., Sulik, M., \& Spinrad, T. (2014). Self-regulation, effortful control, and their socioemotional correlates. In J. Gross (Ed.), Handbook of emotion regulation (2nd ed., pp. 157-172). New York, NY: Guilford Press. 
El Nokali, N. E., Bachman, H. J., \& Votruba-Drzal, E. (2010). Parent involvement and children's academic and social development in elementary school. Child Development, 81, 988-1005. http://dx.doi.org/10 $.1111 / \mathrm{j} .1467-8624.2010 .01447 . \mathrm{x}$

Enders, C., \& Bandalos, D. (2001). The relative performance of full information maximum likelihood estimation for missing data in structural equation models. Structural Equation Modeling, 8, 430-457. http://dx.doi.org/10.1207/S15328007SEM0803_5

Fantuzzo, J., Mcwayne, C., Perry, M., \& Childs, S. (2004). Multiple dimensions of family involvement and their relations to behavioral and learning competencies for urban, low-income children. School Psychology Review, 33, 467-480.

Feldman, R., Greenbaum, C. W., \& Yirmiya, N. (1999). Mother-infant affect synchrony as an antecedent of the emergence of self-control. Developmental Psychology, 35, 223-231. http://dx.doi.org/10.1037/ 0012-1649.35.1.223

Garner, P. W., Mahatmya, D., Moses, L., \& Bolt, E. (2014). Associations of preschool type and teacher-child relational quality with young children's social-emotional competence. Early Education \& Development, 25, 399-420. http://dx.doi.org/10.1080/10409289.2013.801706

Gottfried, A., Gottfried, A., \& Bathurst, K. (2002). Maternal and dualearner employment status and parenting. In M. Bornstein (Ed.), Handbook of parenting: Vol. 2. Biology and ecology of parenting (pp. 207228). Mahwah, NJ: Erlbaum

Greenhaus, J. H., \& Beutell, N. J. (1985). Sources of conflict between work and family roles. The Academy of Management Review, 10, 76-88.

Gresham, F., \& Elliont, S. (1990). Social Skills Rating System manual. Circle Pines, MN: American Guidance Service.

Hook, J. L., \& Wolfe, C. M. (2013). Parental involvement and work schedules: Time with children in the United States, Germany, Norway, and the United Kingdom. European Sociological Review, 29, 411-425. http://dx.doi.org/10.1093/esr/jcr081

Hosokawa, R., Katsura, T., \& Shizawa, M. (2015). The relationship between social skills, fathers' involvement, and economic status in preschool children. Journal of Health Science, 5, 52-57.

Hu, L., \& Bentler, P. (1999). Cutoff criteria for fit indexes in covariance structure analysis: Conventional criteria versus new alternatives. Structural Equation Modeling, 6, 1-55. http://dx.doi.org/10.1080/10705519 909540118

INE. (2011). Censos 2011. [2011 National Census]. Retrieved from http:// censos.ine.pt/xportal/xmain?xpid $=$ CENSOS\&xpgid $=$ censos 2011 apresentacao

Kamphaus, R., \& Reynolds, C. (2006). Parenting Relationship Questionnaire. Minneapolis, MN: NCS Pearson.

Lamb, M. (2000). The history of research on father involvement: An overview. Marriage \& Family Review, 29(2-3), 23-42.

Lang, S. N., Schoppe-Sullivan, S. J., Kotila, L. E., Feng, X., Dush, C. M., \& Johnson, S. C. (2014). Relations between fathers' and mothers' infant engagement patterns in dual-earner families and toddler competence. Journal of Family Issues, 35, 1107-1127. http://dx.doi.org/10.1177/ $0192513 X 14522243$

Lareau, A. (2002). Invisible inequality: Social class and childrearing in black families and white families. American Sociological Review, 67, 747-776. http://dx.doi.org/10.2307/3088916

Lindsey, E., Cremeens, P., Colwell, M., \& Caldera, Y. (2009). The structure of parent-child dyadic synchrony in toddlerhood and children's communication competence and self-control. Social Development, 18, 375-396. http://dx.doi.org/10.1111/j.1467-9507.2008.00489.x

Matias, M., Ferreira, T., Vieira, J. M., Cadima, J., Leal, T., \& Matos, P. M. (2017). Work-family conflict, psychological availability and child emotion regulation: Spillover and crossover in dual-earner families. Personal Relationships, 24, 634-639. http://dx.doi.org/10.1111/pere.12198

McBride, B., \& Mills, G. (1993). A comparison of mother and father involvement with their preschool age children. Early Childhood Re- search Quarterly, 8, 457-477. http://dx.doi.org/10.1016/S08852006(05)80080-8

Meece, D., \& Robinson, C. M. (2014). Father-child interaction: Associations with self-control and aggression among 4.5-year-olds. Early Child Development and Care, 184, 783-794. http://dx.doi.org/10.1080/ 03004430.2013.818990

Meteyer, K., \& Perry-Jenkins, M. (2010). Father involvement among working-class, dual-earner couples. Fathering: A Journal of Theory, Research, and Practice about Men as Fathers, 8, 379-403. http://dx doi.org/10.3149/fth.0803.379

Michel, J., Kotrba, L., Mitchelson, J., Clark, M., \& Baltes, B. (2011). Antecedents of work-family conflict: A meta-analytic review. Journal of Organizational Behavior, 32, 689-725. http://dx.doi.org/10.1002/job .695

Perry-Jenkins, M., Repetti, R., \& Crouter, A. (2000). Work and family in the 1999s. Journal of Marriage and the Family, 62, 981-998. http://dx .doi.org/10.1111/j.1741-3737.2000.00981.x

Pleck, J. (1983). Husbands' paid work and family roles: Current research issues. In H. Lopata \& J. Pleck (Eds.), Research in the interweave of social roles: Families and jobs (pp. 231-333). Greenwich, CT: JAI Press.

Pleck, J. (2010). Paternal involvement: Revised conceptualization and theoretical linkages with child outcomes. In M. Lamb (Ed.), The role of the father in child development (5th ed., pp. 58-93). Hoboken, NJ: Wiley.

Rantanen, J., Kinnunen, U., Pulkkinen, L., \& Kokko, K. (2012). Developmental trajectories of work-family conflict for Finnish workers in midlife. Journal of Occupational Health Psychology, 17, 290-303. http://dx.doi.org/10.1037/a0028153

R Core Team. (2013). R: A language and environment for statistical computing. Vienna, Austria: R Foundation for Statistical Computing. Retrieved from http://www.r-project.org/

Rimm-Kaufman, S., Pianta, R., Cox, M., \& Bradley, R. (2003). Teacherrated family involvement and children's social and academic outcomes in kindergarten. Early Education and Development, 14, 179-198. http:// dx.doi.org/10.1207/s15566935eed1402_3

Rosseel, Y. (2012). lavaan: An R package for structural equation modeling. Journal of Statistical Software, 48, 1-36. http://dx.doi.org/10.18637/jss .v048.i02

Schweizer, K. (2010). Some guidelines concerning the modeling of traits and abilities in test construction. European Journal of Psychological Assessment, 26, 1-2. http://dx.doi.org/10.1027/1015-5759/a000001

Shonkoff, J., \& Phillips, D. (2000). From neurons to neighborhoods: The science of early childhood development. Washington, DC: National Academy Press.

Siu, A., Ma, Y., \& Chui, F. (2016). Maternal mindfulness and child social behavior: The mediating role of the mother-child relationship. Mindfulness, 7, 577-583. http://dx.doi.org/10.1007/s12671-016-0491-2

Taylor, Z. E., Eisenberg, N., Spinrad, T. L., \& Widaman, K. F. (2013) Longitudinal relations of intrusive parenting and effortful control to ego-resiliency during early childhood. Child Development, 84, 11451151. http://dx.doi.org/10.1111/cdev.12054

Thompson, R. (2014). Socialization of emotion and emotion regulation in the family. In J. Gross (Ed.), Handbook of emotion regulation (2nd ed., pp. 173-185). New York, NY: Guilford Press.

Vandenberg, R., \& Lance, C. (2000). A review and synthesis of the measurement invariance literature: Suggestions, practices, and recommendations for organizational research. Organizational Research Methods, 3, 4-70. http://dx.doi.org/10.1177/109442810031002

Vieira, J., Cadima, J., Leal, T., \& Matos, P. M. (2013). Validation of a Portuguese version of the Parenting Relationship Questionnaire. Poster session presented at the meeting of the 16th European Conference on Developmental Psychology, Lausanne, Switzerland. 
Vieira, J., Lopez, F., \& Matos, P. M. (2014). Further validation of workfamily conflict and work-family enrichment scales among Portuguese working parents. Journal of Career Assessment, 22, 329-344. http://dx .doi.org/10.1177/1069072713493987

Vieira, J., Matias, M., Ferreira, T., Lopez, F., \& Matos, P. M. (2016). Parents' work-family experiences and children's problem behaviors: The mediating role of the parent-child relationship. Journal of Family Psycholgy, 30, 419-430. http://dx.doi.org/10.1037/fam0000189

Vieira, J., Matias, M., Lopez, F., \& Matos, P. M. (2016). Relationships between work-family dynamics and parenting experiences: A dyadic analysis of dual-earner couples. Work \& Stress, 30, 243-261. http://dx .doi.org/10.1080/02678373.2016.1211772

Westman, M. (2001). Stress and strain crossover. Human Relations, 54, 717-751. http://dx.doi.org/10.1177/0018726701546002

Williford, A. P., Vick Whittaker, J. E., Vitiello, V. E., \& Downer, J. T. (2013). Children's engagement within the preschool classroom and their development of self-Regulation. Early Education and Development, 24, 162-187. http://dx.doi.org/10.1080/10409289.2011.628270
Wood, J. J., \& Repetti, R. L. (2004). What gets dad involved? A longitudinal study of change in parental child caregiving involvement. Journal of Family Psychology, 18, 237-249. http://dx.doi.org/10.1037/08933200.18.1.237

Yeung, J., Sandberg, J., Davis-Kean, P., \& Hofferth, S. (2001). Children's time with fathers in intact families. Journal of Marriage and Family, 63, 136-154. http://dx.doi.org/10.1111/j.1741-3737.2001.00136.x

Zick, C., Bryant, W. K., \& Österbacka, E. (2001). Mothers' employment, parental involvement, and the implications for intermediate child outcomes. Social Science Research, 30, 25-49. http://dx.doi.org/10.1006/ ssre. 2000.0685

Received September 28, 2016

Revision received July 18, 2017

Accepted September 15, 2017 